\title{
Therapeutic and scintigraphic applications of polymeric micelles: combination of chemotherapy and radiotherapy in hepatocellular carcinoma
}

This article was published in the following Dove Press journal:

International Journal of Nanomedicine

16 December 2015

Number of times this article has been viewed

\author{
Ying-Hsia Shih ${ }^{1,2}$ \\ Cheng-Liang Peng ${ }^{2}$ \\ Ping-Fang Chiang ${ }^{1,2}$ \\ Wuu-Jyh Lin $^{2}$ \\ Tsai-Yueh Luo ${ }^{2,3}$ \\ Ming-Jium Shieh ${ }^{1,4}$ \\ 'Institute of Biomedical Engineering, \\ National Taiwan University, Taipei, \\ Taiwan; ${ }^{2}$ ssotope Application \\ Division, Institute of Nuclear \\ Energy Research, Taoyuan, Taiwan; \\ ${ }^{3}$ Institute of Radiological Science, \\ Central University, Taichung, Taiwan; \\ ${ }^{4}$ Department of Oncology, National \\ Taiwan University Hospital, College of \\ Medicine, National Taiwan University, \\ Taipei, Taiwan
}

Correspondence: Ming-Jium Shieh Institute of Biomedical Engineering, National Taiwan University, I Jen-Ai Road, Section I, Taipei 100, Taiwan Tel +886223123456 ext 1444 Fax +886223940049

Email soloman@ntu.edu.tw

Tsai-Yueh Luo

Isotope Application Division, Institute of Nuclear Energy Research, I,000 Wenhua Road, Jiaan Village, Longtan District,

Taoyuan 32546, Taiwan

Tel +886 3 47। I400 ext 7004

Fax +886 3 47। I 416

Email tylo@iner.gov.tw

\begin{abstract}
This study evaluated a multifunctional micelle simultaneously loaded with doxorubicin (Dox) and labeled with radionuclide rhenium-188 $\left({ }^{188} \mathrm{Re}\right)$ as a combined radiotherapy and chemotherapy treatment for hepatocellular carcinoma. We investigated the single photon emission computed tomography, biodistribution, antitumor efficacy, and pathology of ${ }^{188} \mathrm{Re}$-Dox micelles in a murine orthotopic luciferase-transfected BNL tumor cells hepatocellular carcinoma model. The single photon emission computed tomography and computed tomography images showed high radioactivity in the liver and tumor, which was in agreement with the biodistribution measured by $\gamma$-counting. In vivo bioluminescence images showed the smallest size tumor $(P<0.05)$ in mice treated with the combined micelles throughout the experimental period. In addition, the combined ${ }^{188} \mathrm{Re}$-Dox micelles group had significantly longer survival compared with the control, ${ }^{188} \mathrm{ReO}_{4}$ alone $(P<0.005)$, and Dox micelles alone $(P<0.01)$ groups. Pathohistological analysis revealed that tumors treated with ${ }^{188}$ Re-Dox micelles had more necrotic features and decreased cell proliferation. Therefore, ${ }^{188} \mathrm{Re}$-Dox micelles may enable combined radiotherapy and chemotherapy to maximize the effectiveness of treatment for hepatocellular carcinoma.
\end{abstract}

Keywords: ${ }^{188} \mathrm{Re}$-Dox micelles, radiotherapeutic, chemotherapeutic, hepatocellular carcinoma

\section{Introduction}

Hepatocellular carcinoma (HCC) is one of the most common cancer that causes death and has poor prognosis, resulting in patient survival rates in the range of $3 \%-5 \%{ }^{1}$ However, between $20 \%$ and $35 \%$ of patients are eligible for this invasive procedure due to the delayed diagnosis of $\mathrm{HCC}$ in patients with advanced cancer. ${ }^{2}$ Current treatment modalities for HCC include surgical tumor removal or transcatheter arterial embolization, chemotherapy, and external radiotherapy.

The chemotherapeutic drug doxorubicin (Dox) is commonly used to treat HCC. However, clinical studies have shown its serious side effects, such as dose-dependent cardiotoxicity and hepatotoxicity. ${ }^{3}$ Previous researches recently have revealed that nano-sized carrier enhance the accumulation of Dox in the tumor site and decrease the side effect. ${ }^{4,5}$

Intra-arterial administration of therapeutic radiopharmaceuticals and chemotherapeutic agents can deliver a tumoricidal dose with less non-tumorous hepatic tissue damage. ${ }^{6,7}$ However, transcatheter arterial embolization of yttrium-90 $\left({ }^{90} \mathrm{Y}\right)$-micospheres requires accurate skill and the use of specialized equipment, and the skeletal accumulation of ${ }^{90} \mathrm{Y}$ could result in bone marrow depression. ${ }^{8}$ 
Rhenium-188 $\left({ }^{188} \mathrm{Re}\right)$ is now considered as a better isotope for in vivo studies and clinical applications in both the imaging and therapeutic treatment of HCC. ${ }^{9,10}$ Since ${ }^{188} \operatorname{Re}\left(t_{1 / 2}=16.9\right.$ hours $)$ decays by $15 \%$ gamma emission $\left(E_{\gamma}=155 \mathrm{keV}\right)$ and by $85 \%$ beta emission $\left(E_{\beta-\max }=2.12 \mathrm{meV}\right)$, its incorporation into polymeric micelles, which composed of amphiphilic block copolymers for drug delivery, ${ }^{11-13}$ could have both diagnostic and therapeutic applications. ${ }^{14-19}$ The high $\beta$-energy emission $(2.1 \mathrm{meV})$ of ${ }^{188} \mathrm{Re}$ provides the optimal therapeutic dose and deep tissue penetration for cancer therapy as previously studies described. ${ }^{17,20-22}$ By the enhanced permeability and retention (EPR) effect, nano-sized carrier could passive targeting ${ }^{23}$ and efficiently accumulate in tumors. ${ }^{24-27}$

In this study, we evaluated a nano-sized drug delivery system based on methoxy-poly (ethylene glycol)-blockpoly( $\varepsilon$-caprolactone) (mPEG- $b$-PCL) micelles ${ }^{28}$ containing radiopharmaceuticals $-{ }^{188} \mathrm{Re}$ and chemotherapeutic agents Dox for combined radio/chemotherapy. The multifunctional micelles loaded with Dox and labeled with ${ }^{188}$ Re were developed to synergistically enhance cancer therapy. By using a murine model with luciferase-transfected BNL tumor cells (BNL/Luc) HCC, both the therapeutic efficacy and mechanism of this delivery system were evaluated.

\section{Materials and methods Preparation of ${ }^{188} \mathrm{Re}-\mathrm{Dox}$ micelles}

The amphiphilic block copolymers, including mPEG- $b$-PCL and Fmoc-NH-PEG- $b$-PCL, were synthesized by the ringopening polymerization of $\varepsilon$-caprolactone, and deprotected by $20 \%$ piperidine in dimethylformamide. ${ }^{15,29}$ Conjugation of diethylene triamine pentaacetic acid (DTPA) dianhydride with the amino group of $\mathrm{N}_{2} \mathrm{H}-\mathrm{PEG}-b$-PCL to synthesis the DTPA-PEG- $b$-PCL as described previously. ${ }^{17,30}$ The molecular weights of copolymers were characterized by ${ }^{1} \mathrm{H}$ nuclear magnetic resonance (NMR, Bruker Avance-500 MHz FT-NMR; Bruker Corporation, Billerica, MA, USA) and gel permeation chromatography (Waters 510 pump/410 differential refractometer).

The doxorubicin-loaded DTPA micelles (Dox micelles) were prepared by the solvent evaporation method..$^{29,31,32}$ The concentration of Dox was quantified by determining the absorbance at $480 \mathrm{~nm}$ with a UV-visible spectrophotometer (BioMate 3S, Thermo Electron Corporation, Hudson, NH, USA). The drug encapsulation efficiency is the amount of drug encapsulated divided by the amount of drug added multiplied by $100 \%$. The mean diameters of the micelles were characterized with a Delsa ${ }^{\mathrm{TM}}$ Nano Particle Analyzer (Beckman Coulter, Fullerton, CA, USA). The morphology of the micelles was observed by $\mathrm{H}-7650$ transmission electron microscopy (TEM, Hitachi Ltd., Tokyo, Japan).

The morphology of the micelles was observed by $\mathrm{H}-7650$ TEM (Hitachi Ltd). The radiolabeling yields of the ${ }^{188} \mathrm{Re}-$ DTPA-micelles were determined by a radio-thin layer chromatography imaging scanner (AR2000, Bioscan, Washington, DC, USA). The ${ }^{188} \mathrm{Re}$-Dox micelles were prepared by reacting a mixture of Dox micelles, ${ }^{188} \mathrm{Re}$-perrhenate $\left({ }^{188} \mathrm{ReO}_{4}, \sim 370\right.$ $\mathrm{MBq}$ ), and stannous chloride for 1 hour at $37^{\circ} \mathrm{C} \cdot{ }^{27,28,33,34}$

\section{Measurement of in vitro release}

The in vitro release profiles of ${ }^{188} \mathrm{Re}$ and Dox from the ${ }^{188}$ Re-Dox micelles were studied as described previously. ${ }^{15}$ A $2 \mathrm{~mL}$ volume of ${ }^{188} \mathrm{Re}$-Dox micelles were placed in a dialysis bag (molecular weight cutoff $3.5 \mathrm{kDa}$ ), and the dialysis bag was incubated in $50 \mathrm{~mL}$ of phosphate-buffered saline (PBS) ( $\mathrm{pH} \sim 7.4$ ) with gently stirring at $37^{\circ} \mathrm{C}$, and the release medium was collected at predetermined time intervals. The release of Dox was quantified using high-performance liquid chromatography (HPLC), using a Waters Symmetry C18 reversed-phase column $(150 \mathrm{~mm} \times 3.9 \mathrm{~mm}, 5 \mathrm{~mm})$ and a Waters HPLC instrument (Waters HPLC Alliance 2695 with a Waters 2487 dual $\lambda$ absorbance detector; Waters, Milford, MA, USA). The mobile phase consisted of a $0.1 \%$ trifluoroacetic acid solution $(\mathrm{pH}=3.0)$ and acetonitrile at a flow rate of $1 \mathrm{~mL} / \mathrm{min}$. Dox was detected using a $\lambda$ absorbance detector with a wavelength of $480 \mathrm{~nm}$. The released ${ }^{188} \mathrm{Re}$ from the

${ }^{188}$ Re-Dox micelles was quantified using a gamma-counter (Cobra series Model 5003, Packard Instrument Company, Inc., Meriden, CT, USA). All results are the mean \pm standard deviation.

\section{Establishment of the murine hepatocellular carcinoma model}

Orthotopic murine liver tumor was generated in Balb/c mice using the BNL/Luc cell line. Female Balb/c athymic (nut/ nut) nude mice 5-6 weeks of age were purchased from the National Laboratory Animal Center (Taipei, Taiwan). The in vivo experimental protocols were approved by the College of Medicine and the College of Public Health Institutional Animal Care and Use Committee (National Taiwan University; IACUC, number 20130041). All experiments involving the $\mathrm{BNL} /$ Luc cell line were performed in accordance with the rules of the Biosafety Level 2 Laboratory. The BNL/Luc cells were cultured in a humidified $5 \% \mathrm{CO}_{2}$ incubator at $37^{\circ} \mathrm{C}$ in Dulbecco's Modified Eagle's Medium (Gibco BRL, Gaithersburg, MD, USA), containing 10\% fetal bovine serum (Gibco BRL) and 1\% antibiotics (antibiotic-antimycotic; Gibco BRL). The BNL/Luc tumors were established by 
orthotopic injection of $10^{5}$ cells into one capsule of hepatic lobes. After 7 days post-incubation, the mice were monitored by bioluminescence imaging using IVIS imaging system (Xenogen, Alameda, CA, USA) to check for tumor growth. Mice were anesthetized and intraperitoneally injected with D-luciferin (Xenogen) for bioluminescence imaging.

\section{Micro-SPECT/CT and biodistribution of ${ }^{188}$ Re-micelles}

Micro-single photon emission computed tomography (SPECT)/computed tomography (CT) was also performed to evaluate the distribution of the ${ }^{188} \mathrm{Re}$-Dox micelles in the mice bearing orthotopic BNL/Luc tumors. SPECT and CT images were obtained from micro-SPECT/CT scanner system (XSPECT, Gamma Medica, Northridge, CA, USA). Mice bearing BNL/Luc tumors were received the ${ }^{188} \mathrm{Re}-\mathrm{Dox}$ micelles (equivalent to $22.2 \mathrm{MBq}$ of ${ }^{188} \mathrm{Re}$ ) when that tumors volume reached $150-200 \mathrm{~mm}^{3}$. After intravenous injection 1, 4, 24, and 48 hours, the SPECT images merged with CT images were obtained from the animal in exactly the same position as described previously. ${ }^{17}$

The tumor-bearing mice ( $\mathrm{n}=3$ per time point) were sacrificed 1, 4, 8, 24, and 48 hours after injection of ${ }^{188} \mathrm{Re}$-Dox micelles, and then the blood, heart, liver, spleen, lung, kidney, smooth muscle, small intestine, urinary bladder, bone, brain, and tumors were collected, and the radioactivity of those organs was measured by a gamma counter. Distribution data were shown as the percentage of injected dose per gram of organs (ID\%/g). Each column represents the mean \pm standard deviation.

The biodistribution of doxorubicin was studied by ex vivo fluorescence images using an IVIS imaging system. After ${ }^{188}$ Re-Dox micelles injected 48 hours, the mice were sacrificed and obtained the heart, liver, spleen, lung, kidney, intestine, and tumors. Aforementioned organs were isolated to estimate the organs distribution of doxorubicin.

After the biodistribution studies, tumors and livers of mice were frozen, and embedded in optimal cutting temperature compound (Tissue Tek, Sakura, Torrance, CA, USA) for the frozen sections. The frozen sections were placed in contact with a BASMS 2040 imaging plate (Fujifilm, Tokyo, Japan) for the autoradiography, and the images were analyzed by an FLA-5100 reader (Fujifilm) and Multi Gauge V3.0 software (Fujifilm).

To identify the cluster of differentiation 31 (CD-31) expression and the distribution of doxorubicin in the tumor tissues $(n=3)$ by immunofluorescence staining, the BNL/Luc tumor-bearing mice were intravenously administered with ${ }^{188} \mathrm{Re}$-Dox micelles at $10 \mathrm{mg} / \mathrm{kg}$ of doxorubicin. The tumor tissues were collected at 24 and 48 hours after injection, frozen, optimal cutting temperature embedded, and sectioned. The sections were washed continuous three times with PBS, then fixed in acetone for 15 minutes. The sections slide was farther blocked with 5\% normal goat serum for 10 minutes at room temperature. The rat-anti-mouse CD-31 monoclonal antibody (rat anti-mouse, diluted 1:100, BioLegend, San Diego, CA, USA) were overlaid all sections with at $4^{\circ} \mathrm{C}$ overnight. The fluorescein isothiocyanate-labeled goat-anti-rat IgG (diluted 1:400, Sigma, St Louis, MO, USA) was added on slide and incubated at room temperature for 1 hour. The CD-31 staining slides were observed under a fluorescence microscope (Olympus Corporation, Tokyo, Japan).

\section{Anti-tumor efficacy of ${ }^{188}$ Re-Dox micelles}

The mice implanted with BNL/Luc tumor were assigned to four groups as follows: control-PBS $(n=4),{ }^{188} \mathrm{ReO}_{4}(n=4)$, Dox micelles ( $\mathrm{n}=5)$, and ${ }^{188} \mathrm{Re}-\mathrm{Dox}$ micelles $(\mathrm{n}=5)$. The ${ }^{188} \mathrm{Re}-\mathrm{Dox}$ micelles were administered via the tail vein with $10 \mathrm{mg} / \mathrm{kg}$ of doxorubicin and $22.2 \mathrm{MBq}$ of ${ }^{188} \mathrm{Re}$ on days 0,6 , and 12 . Body weight changes were measured during observation days. The mice death dates were recorded for the survival curve by the Kaplan-Meier method. Survival evaluate of all groups was analyzed by log-rank test, and when $<0.05, P$-value was considered significant difference. The tumor growth inhibition (TGI) percentage of mice was calculated by the relative tumors volume at the mice sacrificed time points.

The therapeutic responses were monitored by bioluminescence imaging during observation days. The BNL/Luc tumor of mice was imaged and measured by IVIS system by Living Imaging software (Xenogen) on days $0,6,13$, 19 , and 26.

The ${ }^{188} \mathrm{Re}-\mathrm{Dox}$ micelles were administered via the tail vein with $10 \mathrm{mg} / \mathrm{kg}$ of doxorubicin and $22.2 \mathrm{MBq}$ of ${ }^{188} \mathrm{Re}$. The tumor tissues $(n=3)$ were collected at 24, 36, 48 hours after injection. For the hematoxylin and eosin (H\&E) staining and immunohistochemical studies, all of the tumor tissues were formalin-fixed and paraffin-embedded. The necrosis in tumor tissue was detected by nicotinamide adenine dinucleotide phosphate (NADPH)-diaphorase staining. ${ }^{35}$ The section slides were reacted with NADPH-diaphorase reaction solution (10 mL of $1 \mathrm{M}$ Trizma solution) containing $80 \mathrm{mg}$ NADPH and $5 \mathrm{mg}$ nitroblue tetrazolium for 30 minutes at $37^{\circ} \mathrm{C}$. The section slides were also analyzed by proliferating cell nuclear antigen (PCNA) immunohistochemical staining for the proliferation study as described previously. ${ }^{18}$ The liver and spleen tissues $(n=3)$ were collected at 24, 48 hours, and 7 days after the injection of the ${ }^{188}$ Re-Dox micelles for H\&E staining. 


\section{Statistical analysis}

All results are the mean \pm standard deviation from ten distinct regions of each of the three tumors per experimental group.

\section{Results \\ Characterization of the ${ }^{188}$ Re-Dox micelles}

We synthesized mPEG-b-PCL and DTPA-PEG-b-PCL as described previously (Figure 1A). ${ }^{17}$ The molecular weights $\left(\mathrm{M}_{\mathrm{n}, \mathrm{NMR}}\right)$ and degree of polymerization $\left(\mathrm{DP}_{\mathrm{PCL}}\right)$ of mPEG-bPCL and DTPA-PEG-b-PCL copolymers were 15,400 Da $\left(\mathrm{DP}_{\mathrm{PCL}}\right.$ : 91.1) and $14,000 \mathrm{Da}\left(\mathrm{DP}_{\mathrm{PCL}}: 78.9\right)$, respectively, as determined by ${ }^{1} \mathrm{H}$ NMR spectroscopy. The conjugation efficiency of DTPA dianhydride to $\mathrm{NH}_{2}$-PEG-PCL was $76.8 \%$ as described previously. ${ }^{17}$ The Dox micelles were observed by TEM (Figure 1B), exhibited spherical shape with sizes consistent with those observed by DLS (Figure 1C). The size of Dox micelles using various $\mathrm{D} / \mathrm{P}$ ratios for Dox loading ranged from 107.5 to $194.0 \mathrm{~nm}$ (Table 1 and Figure 1C). The radiochemical purities of the ${ }^{188} \mathrm{Re}$-Dox micelles with $\mathrm{D} / \mathrm{P}$ ratios of $1: 5,1: 10$, and $1: 20$ were $89.4 \%, 94.1 \%$, and $90.1 \%$, respectively (Figure 1D). The Dox micelles with a $\mathrm{D} / \mathrm{P}$ ratio of $1: 5$ or 1:20 were larger in particle sizes with lower encapsulation efficiencies and radiochemical purities than those with a D/P ratio of 1:10 (Table 1).

The in vitro release profiles of ${ }^{188} \mathrm{Re}$ (Figure $2 \mathrm{~A}$ ) and Dox (Figure 2B) from the ${ }^{188} \mathrm{Re}-\mathrm{Dox}$ micelles in PBS solution at pH 5.0 and 7.4 were assessed. A two-phase release profile was detected with a relatively fast release in the first phase after 8 hours, followed by a sustained and slower release over a prolonged period of time.

\section{Micro-SPECT/CT imaging and biodistribution of the ${ }^{188} \mathrm{Re}-\mathrm{D}$ ox micelles in mice bearing $B N L / L u c$ tumors}

The biodistributions of the ${ }^{188} \mathrm{Re}$-Dox micelles were evaluated in mice bearing BNL/Luc tumors. The micro-SPECT/ CT imaging discovered that the radioactivity accumulated in both the liver and tumor at 1, 4, 24, and 48 hours after the injection of the ${ }^{188} \mathrm{Re}-\mathrm{Dox}$ micelles (Figure 3A). To confirm the biodistributions of the ${ }^{188} \mathrm{Re}$-Dox micelles from the micro-SPECT/CT images, autoradiography was performed. The autoradiography studies clearly showed significant accumulation of radioactivity from the ${ }^{188} \mathrm{Re}$-Dox micelles in the liver beginning 4 hours after injection (Figure 3B). However, the tumor accumulation of radioactivity also increased with time after the injection.
The highest accumulation had occurred in the liver, followed by in the tumor, spleen, lung, and kidney at 1 hour after the injection of the ${ }^{188} \mathrm{Re}$-Dox micelles (Figure 3C). The radioactivity in the blood and kidney decreased quickly over the time course, with the urinary bladder displaying increased radioactivity.

The ex vivo biodistribution of Dox was evaluated in mice bearing BNL/Luc tumors. Images obtained by the IVIS imaging system revealed the accumulation of Dox in the heart, liver, tumor, spleen, lung, and kidney at 48 hours after the injection of the ${ }^{188}$ Re-Dox micelles. As shown in Figure 4A-C, higher bioluminescence and fluorescence from Dox occurred in the tumor compared with other major organs.

The distribution of Dox correlation with the blood vessels between liver and tumor was evaluated; tissue sections were stained with a CD-31 immunostaining (Figure 4D). This analysis shown that the ${ }^{188}$ Re-Dox micelles extravagated from the blood vessels and that doxorubicin delivery was more accumulation in tumors compared with in normal liver.

\section{Anti-tumor effect of the ${ }^{188}$ Re-Dox micelles}

We investigated the antitumor efficacy and toxicity of the ${ }^{188} \mathrm{Re}$-Dox micelles on BNL/Luc tumor-bearing mice (Figure 5). The therapeutic responses were monitored by bioluminescence imaging after various treatments during the evaluation period. Four groups of Balb/c mice bearing orthotopic BNL/Luc tumors were treated with an intravenous injection of combined ${ }^{188} \mathrm{Re}$-Dox micelles, with ${ }^{188} \mathrm{ReO}_{4}$ alone, with Dox-micelles alone, or with PBS. Anti-tumor effect of the ${ }^{188} \mathrm{Re}$-Dox micelles was shown a series of typical optical images of luminescence-expressing tumors after the various treatments (Figure 5A). Mice in the PBS-control and in the ${ }^{188} \mathrm{ReO}_{4}$ alone group shown rapid progression of the tumor burden.

The antitumor efficacy of the ${ }^{188} \mathrm{Re}$-Dox micelles was compared with that of the ${ }^{188} \mathrm{ReO}_{4}$ and the Dox-micelles. As shown in Figure 5B, the tumor burden was measured and quantified based on the luminescence intensity, as performed in Figure 5A. The average photon flux was measured as a function of time after the treatments. The ${ }^{188} \mathrm{Re}$-Dox micelle group gave the lowest photon collection, which suggests the best antitumor efficacy on days 13, 19, and 26 (compared with the control groups of ${ }^{188} \mathrm{ReO}_{4}$ alone and of Dox micelle alone). As expected, the mice that received the combined ${ }^{188}$ Re-Dox micelle treatment exhibited the lowest tumor burden, as shown in Figure 5C. Reduced tumor volumes were measured at the sacrificed time points (day 31) after the combined 

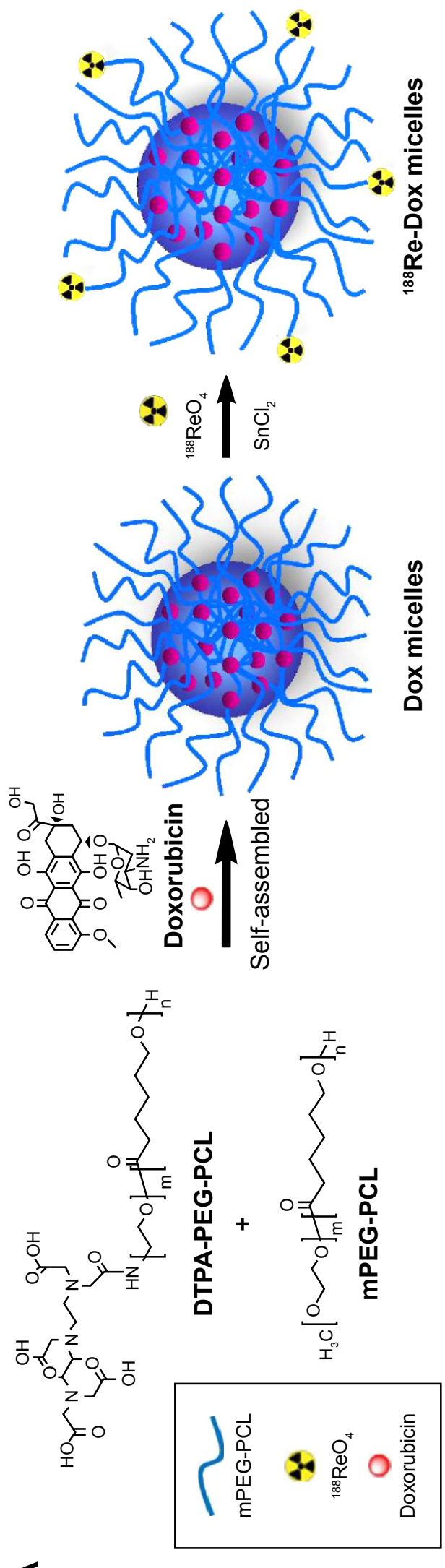

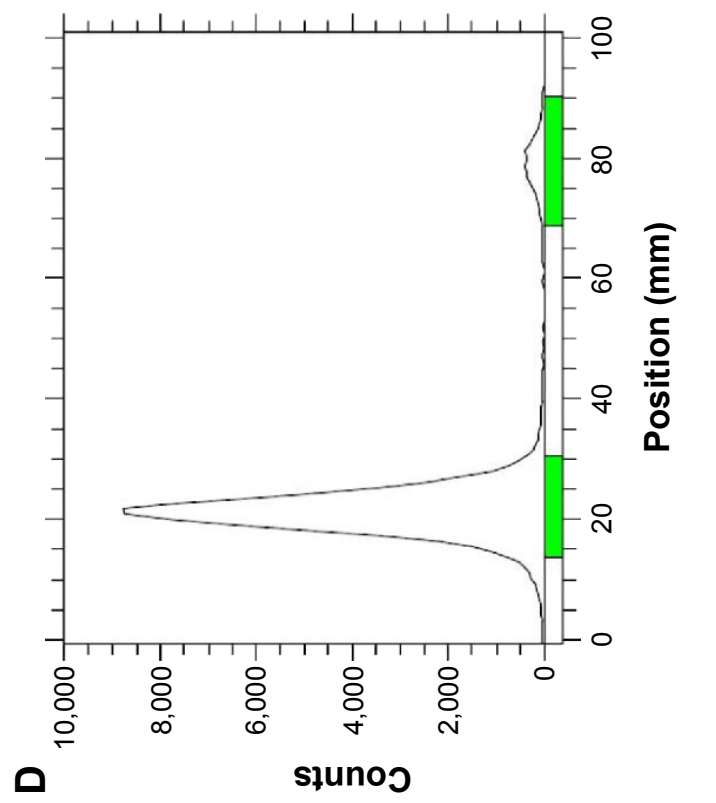

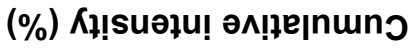

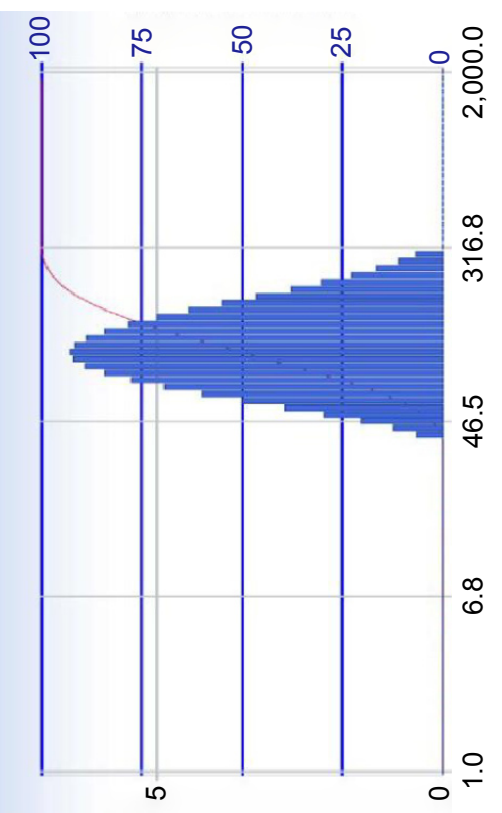

u

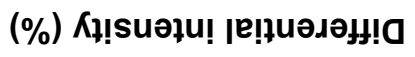

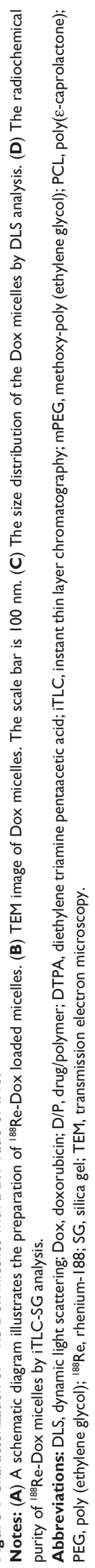


Table I Characteristics of ${ }^{188}$ Re-Dox micelles

\begin{tabular}{llllll}
\hline Polymer & D:P ratio & $\begin{array}{l}\text { Encapsulation } \\
\text { efficiency (\%) }\end{array}$ & $\begin{array}{l}\text { Drug } \\
\text { content (\%) }\end{array}$ & $\begin{array}{l}\text { Mean size } \\
\text { nm (PDI) }\end{array}$ & $\begin{array}{l}\text { Radiochemical } \\
\text { purity (\%) }\end{array}$ \\
\hline mPEG-b-PCL:DTPA- & $1: 5$ & 87.7 & 14.8 & $152.5(0.308)$ & 89.4 \\
PEG-b-PCL ratio =9:1 & & & & & \\
& $1: 10$ & 98.2 & 8.9 & $107.5(0.278)$ & 94.1 \\
& $1: 20$ & 83.1 & 4.0 & $194.0(0.302)$ & 90.1 \\
\hline
\end{tabular}

Notes: ${ }^{a} \mathrm{D}: \mathrm{P}$ ratio $=$ weight of Dox:weight of polymer. ${ }^{\mathrm{b}}$ Dox encapsulation efficiency $(\%)=\left(\right.$ weight of doxorubicin in the micelles/weight of the feeding Dox $\times 100 \%$. ${ }^{\mathrm{D}}$ Drug content $(\%)=($ weight of Dox $) /($ weight of Dox + weight of polymer $) \times 100 \%$. ${ }^{\mathrm{d}}$ As determined by DLS after filtration through a $0.22 \mu \mathrm{m}$ filter. ${ }^{\mathrm{e}} \mathrm{Radiochemical}$ purity as analyzed by iTLC. Abbreviations: DTPA-PEG-b-PCL, diethylene triamine pentaacetic acid poly (ethylene glycol)-block-poly( $\varepsilon$-caprolactone); DLS, dynamic light scattering; Dox, doxorubicin; D, drug; iTLC, instant thin layer chromatography; mPEG-b-PCL, methoxy-poly (ethylene glycol)-block-poly( $\varepsilon$-caprolactone); P, polymer; PDI, polydispersity index; ${ }^{188}$ Re, rhenium- I88.

treatment with the ${ }^{188}$ Re-Dox micelles compared with the control single treatment groups $(P<0.05)$. After the treatment with the ${ }^{188}$ Re-Dox micelles, a TGI percentage of $84.8 \%$ was detected compared with the control. TGI percentage of $42.0 \%$ and $60.7 \%$ was detected for the treatments of ${ }^{188} \mathrm{ReO}_{4}$ alone and Dox-micelles alone, respectively.

Decrease in body weight was recorded to monitor treatment-induced toxicity (Figure 5D). The control groups treated with PBS, ${ }^{188} \mathrm{ReO}_{4}\left(22.2 \mathrm{MBq}\right.$ of $\left.{ }^{188} \mathrm{Re}\right)$ alone, or Dox-micelles (10 mg/kg of Dox) alone gradually increased in mean body weight by $122 \%, 106 \%$, and $113 \%$, respectively, from days 19 to 26 . Two of the four mice died after the second dose of ${ }^{188} \mathrm{ReO}_{4}$ on day 6 . Mice treated with the ${ }^{188} \mathrm{Re}-$ Dox micelles $(10 \mathrm{mg} / \mathrm{kg}$ of doxorubicin and $22.2 \mathrm{MBq}$ of ${ }^{188} \mathrm{Re}$ ) had lost a maximum of approximately $5 \%$ of their weight on day 23 .

We also compared the long-term survival of the mice bearing $\mathrm{BNL} / \mathrm{Luc}$ tumors in the PBS $(\mathrm{n}=4),{ }^{188} \mathrm{ReO}_{4}$ alone

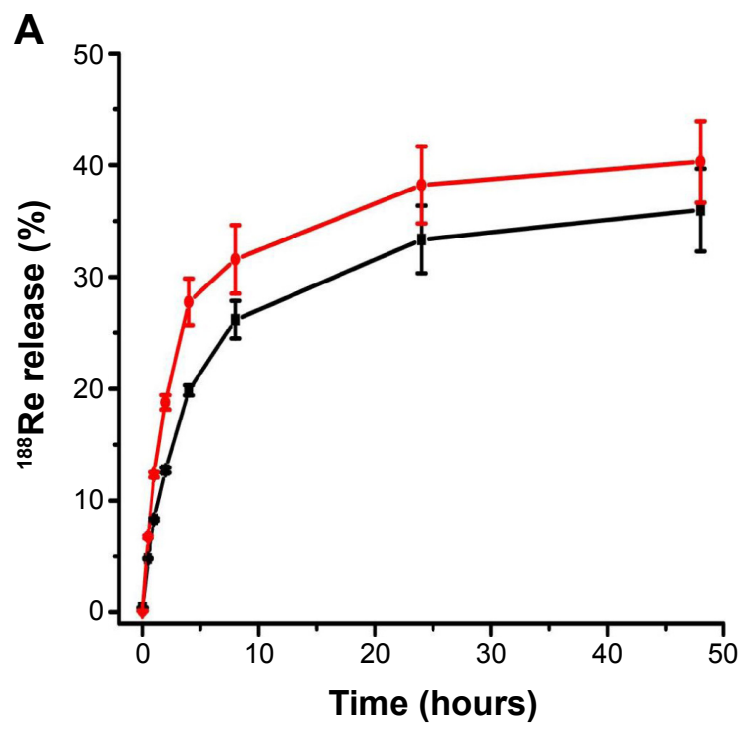

$(n=4)$, Dox micelles alone $(n=5)$, and ${ }^{188}$ Re-Dox micelle $(n=5)$, respectively. Figure 5E shows all mice in the control, ${ }^{188} \mathrm{ReO}_{4}$ alone, and Dox micelles alone of single treatment groups had died owing to aggressive tumor growth by day 31 . The average survival times were $25.7,16.5$, and 24.4 days for the control, ${ }^{188} \mathrm{ReO}_{4}$ alone, and Dox micelle alone groups, respectively. There was no significant difference among the average survival times of these three groups $(P>0.05)$. On the contrary, the survival rates of the hepatoma mice treated with the ${ }^{188}$ Re-Dox micelles were $80 \%$ on day 31 .

To further examine the therapy effect of the ${ }^{188} \mathrm{Re}-\mathrm{Dox}$ micelle in vivo, the tumors were further analyzed by immunohistochemical staining (Figure 6A). The H\&E staining showed different tumor tissue morphologies in different treatment groups. The image of ${ }^{188}$ Re-Dox micelles treat group was found more necrotic tissue in the tumors, compared with control and other groups. In contrast, less necrosis was observed in tumors treated with ${ }^{188} \mathrm{ReO}_{4}$ alone

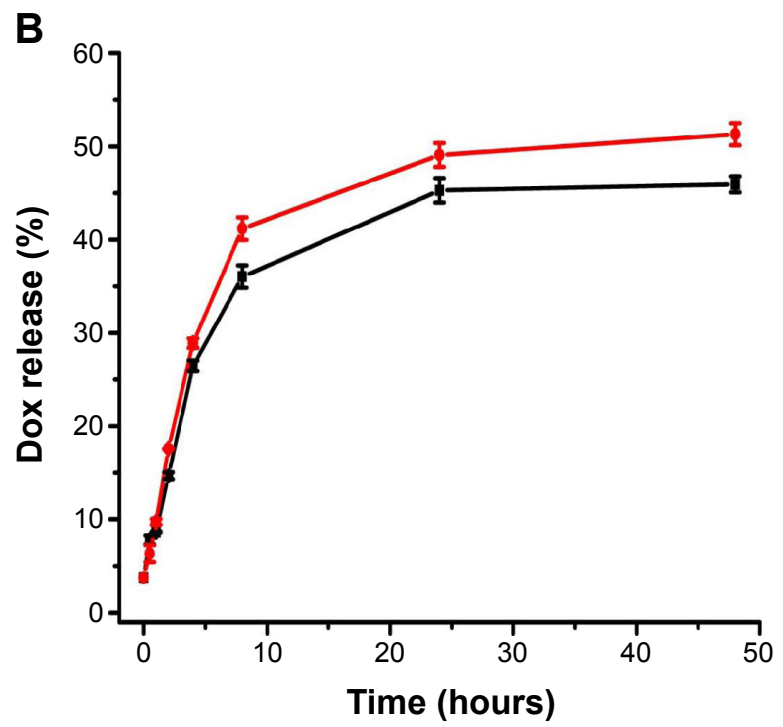

Figure 2 Release profiles of (A) ${ }^{188} \mathrm{Re}$ and (B) Dox from ${ }^{188} \mathrm{Re}-\mathrm{Dox}$ micelles in $\mathrm{pH} 5.0$ and pH 7.4 PBS solution. Note: $n=3$, mean \pm SD.

Abbreviations: Dox, doxorubicin; PBS, phosphate buffered saline; ${ }^{188} \mathrm{Re}$, rhenium- 188; SD, standard deviation. 

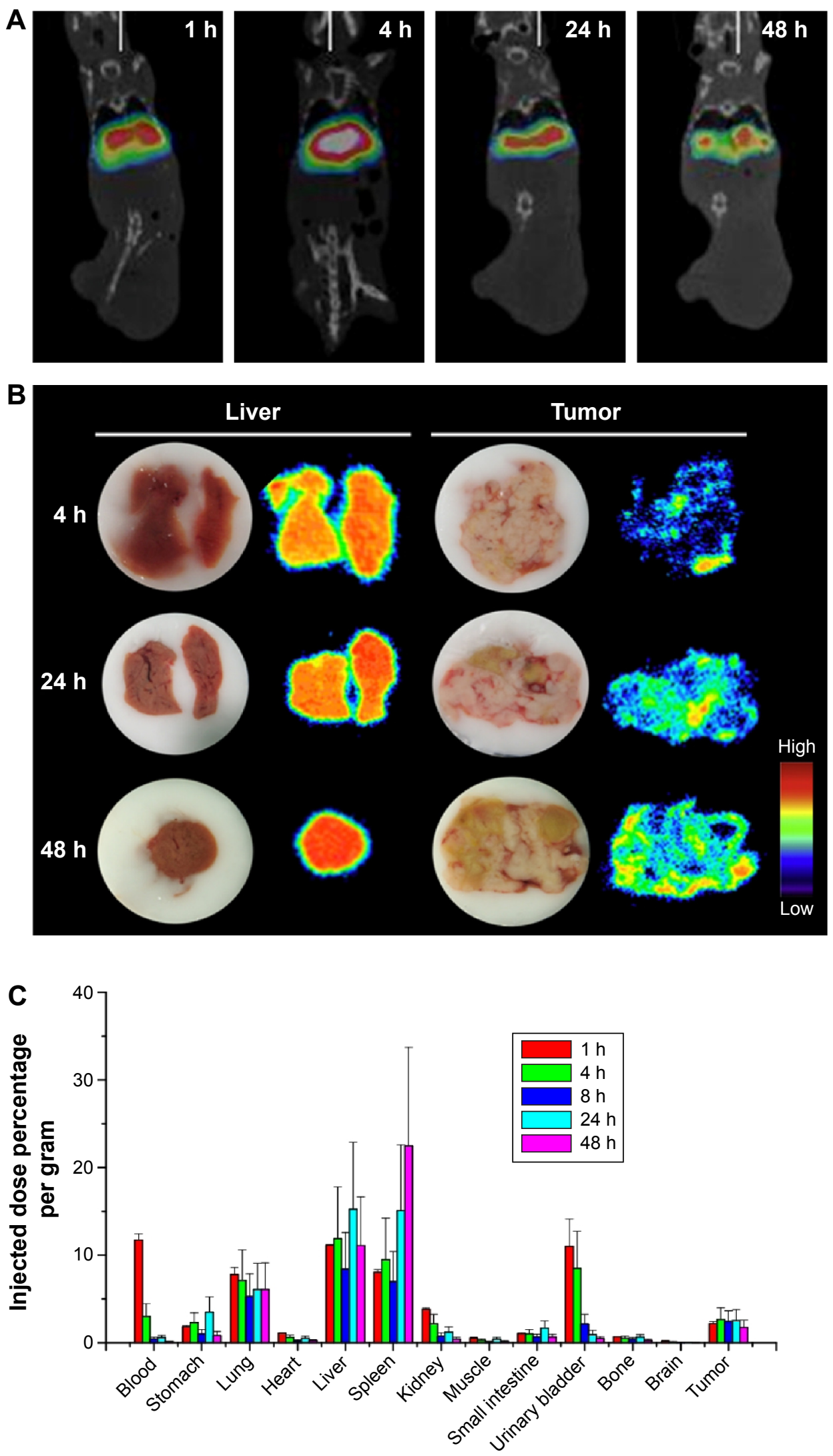

Figure 3 Biodistribution of the ${ }^{188}$ Re-Dox micelles in mice bearing BNL/Luc tumors.

Notes: (A) Representative micro-SPECT and CT images of mice were captured at I, 4, 24, and 48 hours after intravenous injection of ${ }^{188}$ Re-Dox micelles. (B) Representative autoradiographies of excised livers and tumors after administration. (C) Biodistribution of ${ }^{188}$ Re-Dox micelles in major organs of the mice after intravenous injection I, 4, 8, 24 , and 48 hours. Each column represents the mean \pm SD.

Abbreviations: CT, computed tomography; Dox, doxorubicin; h, hours; SD, standard deviation; SPECT, single-photon emission computed tomography; ${ }^{188}$ Re, rhenium- 188 . 
A

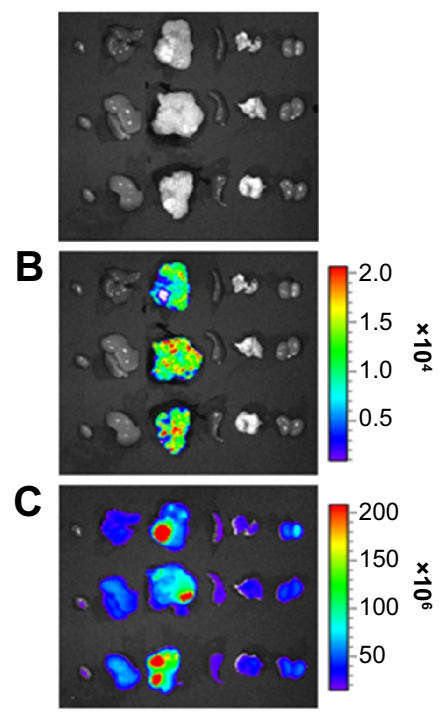

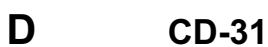
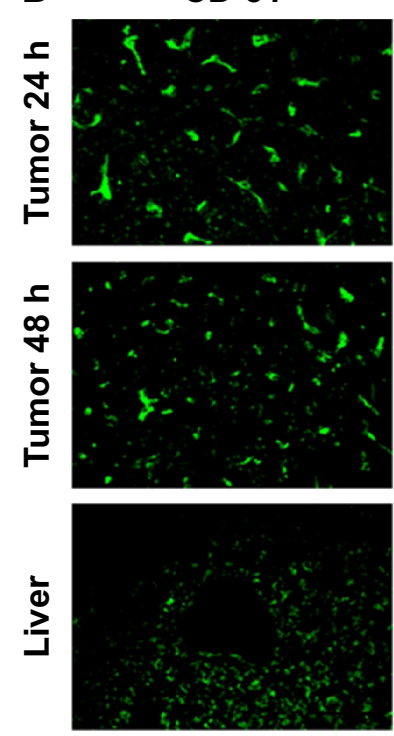
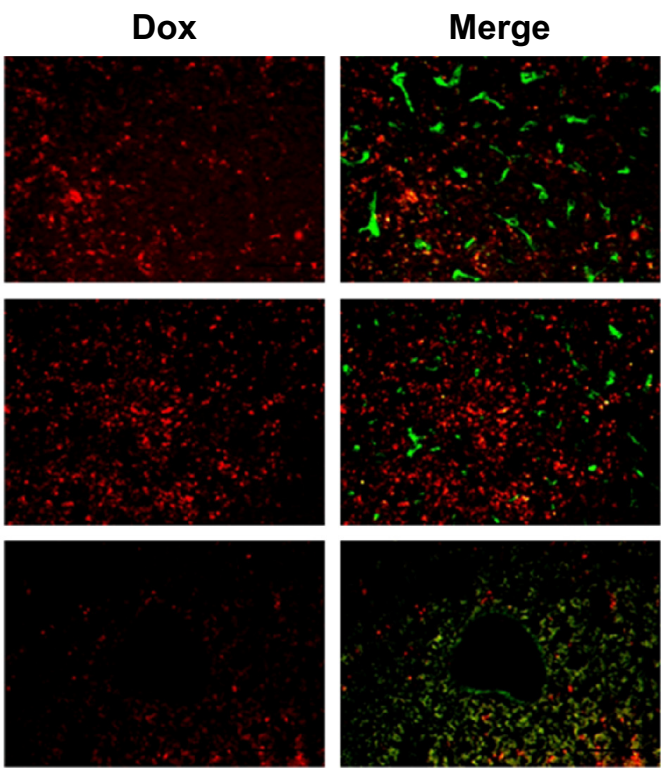
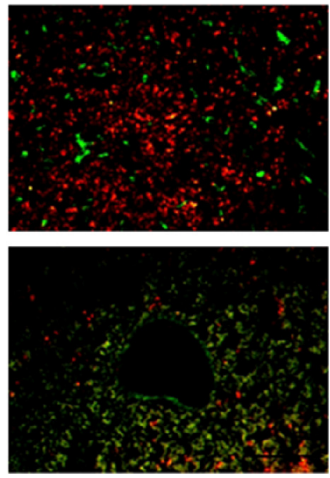

Figure 4 Ex vivo bioluminescence and fluorescence images of various organs postintravenous injection 48 hours of ${ }^{188}$ Re-Dox micelles.

Notes: (A) Standard photographs, (B) bioluminescence imaging, and (C) fluorescence imaging of the major organs and tumors of hepatocellular carcinoma mice. From left to right, the organs are heart, liver, tumor, spleen, lung, and kidney, respectively. (D) Fluorescence microscopic images of ${ }^{188}$ Re-Dox micelles in tumors and in the liver. The red fluorescence specifies the doxorubicin localization. The green fluorescence of CD-3I specifies blood vessels.

Abbreviations: CD-3I, cluster of differentiation 3I; Dox, doxorubicin; IVIS, in vivo imaging system; ${ }^{188} \operatorname{Re}$, rhenium-I88; h, hours.

or control. The PCNA immunostaining revealed that the cell proliferation was significantly decreased in the tumors treated with the ${ }^{188}$ Re-Dox micelles $(\sim 19.6 \% \pm 6.8 \%)$ compared with the tumors treated with ${ }^{188} \mathrm{ReO}_{4}$ alone $(\sim 50.7 \% \pm 8.7 \%$; $P<0.05)$, with Dox micelles alone $(\sim 50.7 \% \pm 8.7 \% ; P<0.05)$, or with PBS alone (control mice) $(\sim 68.0 \% \pm 9.6 \% ; P<0.05)$ (Figure 6B). The histological analysis demonstrated that ${ }^{188}$ Re-Dox micelles could not cause significant toxicity in normal liver and spleen as shown in Figure 6C.

\section{Discussion}

The Dox micelles with a D/P ratio of 1:10 had the highest encapsulation efficiency of $98.2 \%$ and a radiochemical purity of $94.1 \%$ (Figure 1 and Table 1). It had reported that nanoparticles with a size arranging from 10 to $100 \mathrm{~nm}$ are more efficient as drug delivery systems and exhibit high cellular uptake and tumor accumulation, ${ }^{25-27}$ whereas the reticuloendothelial system filters away nanoparticles with sizes larger than $200 \mathrm{~nm} .{ }^{36,37}$ The Dox micelle with a D/P ratio of 1/10 was employed as the drug carrier for this study.

Results of in vitro release profiles of ${ }^{188} \mathrm{Re}$ and Dox indicate that the drug release from the ${ }^{188} \mathrm{Re}$-Dox micelles would occur under acidic or neutral conditions, which is under physiological conditions (Figure 2).

The ${ }^{188}$ Re-Dox micelles could maintain the ${ }^{188} \mathrm{Re}$ and micelles in the liver and tumor area until 48 hours. There was no significant accumulation of radioactivity found in any other organs through SPECT imaging (Figure 3). The biodistributions of the ${ }^{188} \mathrm{Re}$-Dox micelles were also determined by $\gamma$-counting. The results suggested that the ${ }^{188} \mathrm{Re}$-Dox micelles were distributed to most of the major organs and the tumor. Biodistribution studies of the ${ }^{188} \mathrm{Re}-\mathrm{D} o x$ micelles results (Figure 3) implied that the radioactivity of the ${ }^{188}$ Re-Dox micelles was eliminated by the urinary system. The tumorto-muscle ratio of the ${ }^{188} \mathrm{Re}$-Dox micelles increased from $92.97 \pm 98.15$ at 1 hour after the injection to $229.88 \pm 23.10$ at 48 hours after the injection. This result could be explained by the EPR effect, where the ${ }^{188}$ Re-Dox micelles could passively target to tumors site. The greater accumulation of Dox in the BNL/Luc tumor could propose an improved antitumor efficacy with low toxicity caused by nonspecific targeting. ${ }^{38,39}$

Although the results of autoradiography clearly shown significant accumulation of the ${ }^{188}$ Re-Dox micelles in the liver (Figure 3), the fluorescence of doxorubicin in the liver was low. The fluorescence images were obtained from the tissue sections shown similar biodistribution of doxorubicin as that acquired by IVIS imaging (Figure 4). The tumor displayed a higher accumulation of Dox than the liver tissue at 24 and 48 hours following the ${ }^{188} \mathrm{Re}$-Dox micelle delivery. This could be explained by the absence of doxorubicin release from the ${ }^{188} \mathrm{Re}$-Dox micelles in the liver. Consequently, the ${ }^{188} \mathrm{Re}$-Dox micelles would probably not induce significant hepatotoxicity. On the contrary, there was significant fluorescence of 
A
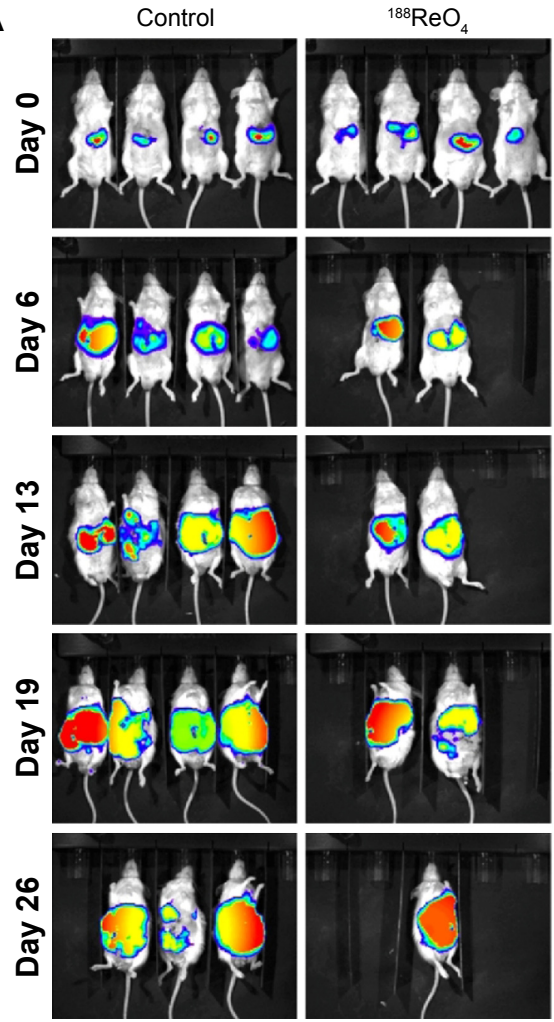

B

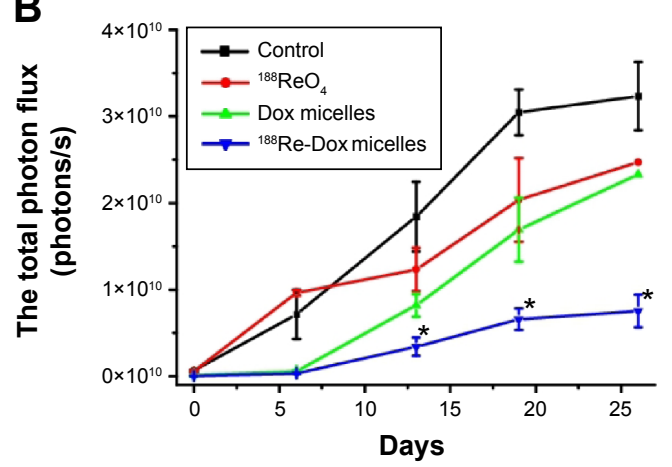

D

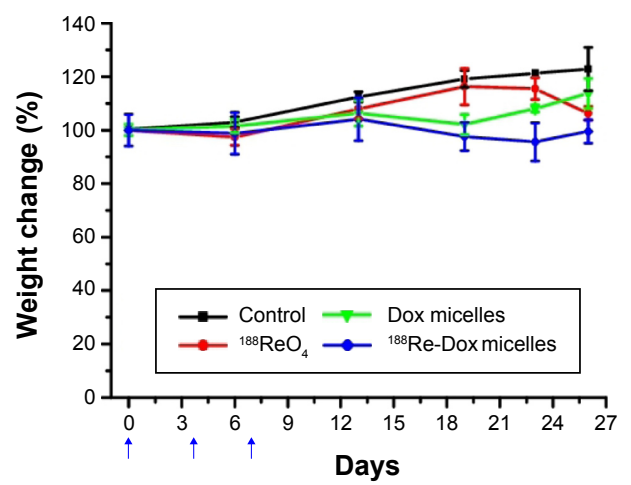

Dox micelles
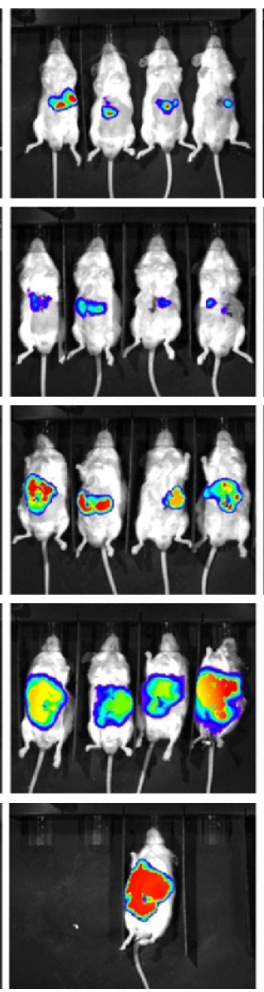

${ }^{188} \mathrm{Re}-$ Dox micelles

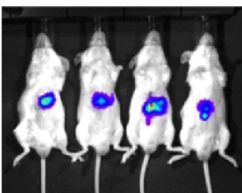

$-250$

$-200$

$150 \stackrel{x}{0}$

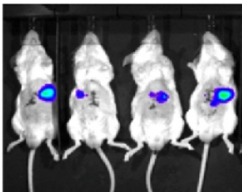

$-100$

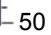

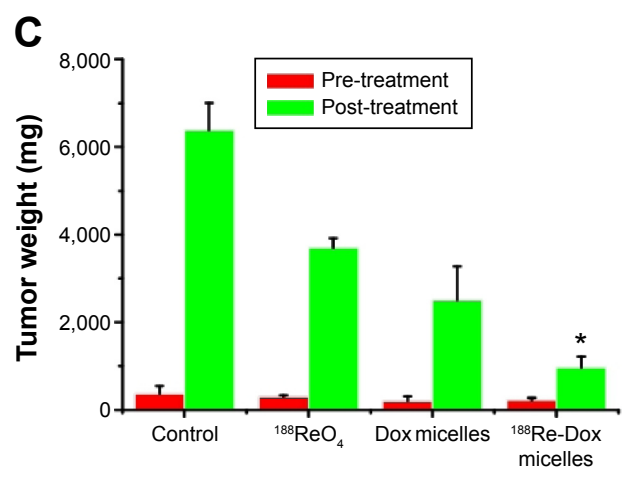

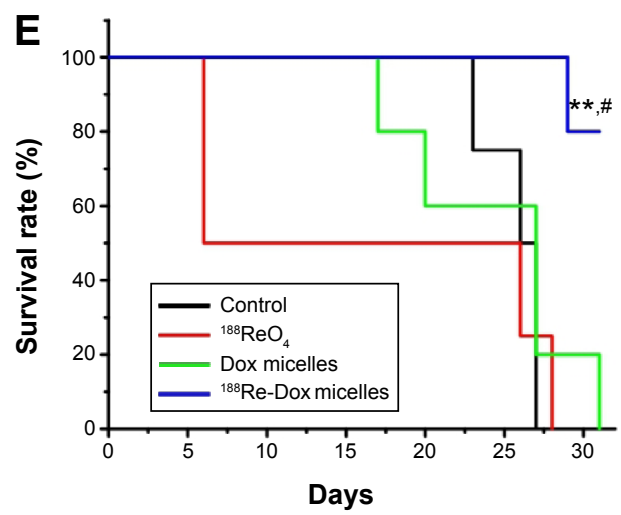

Figure 5 The antitumor efficacy of ${ }^{188} \mathrm{Re}$-Dox micelles in BNL/Luc bearing mice hepatocellular carcinoma.

Notes: (A) Time-lapse luciferin-imaging of mice bearing BNL/Luc hepatocellular carcinoma after the treatment with saline (control), ${ }^{188} \mathrm{ReO}_{4}$ alone, Dox micelles alone, or ${ }^{188}$ Re-Dox micelles. (B) Quantification of luciferase expression in (A). The total photon flux (photons/second) was used to obtain from the luminescence images with Living Image software. (C) The tumor volumes were measured before treatment and at the sacrificed time points. (D) Body weight changes and (E) Kaplan-Meier survival curves of mice bearing BNL/Luc tumors after treatment. The blue arrows indicate the drug injection times. The results represent the mean \pm SD. $* P<0.05$ compared with other treatments. The survival rate data comparison were performed using the log-rank test; $* * P<0.01$ was compared with Dox micelles; ${ }^{*} P<0.005$ was compared with control and ${ }^{188} \mathrm{ReO}_{4}$.

Abbreviations: BNL/Luc, luciferase-transfected BNL tumor cells; Dox, doxorubicin; ${ }^{188}$ Re, rhenium- 188 ; ${ }^{188}$ ReO ${ }_{4}{ }^{188}$ Re-perrhenate; SD, standard deviation. 
A
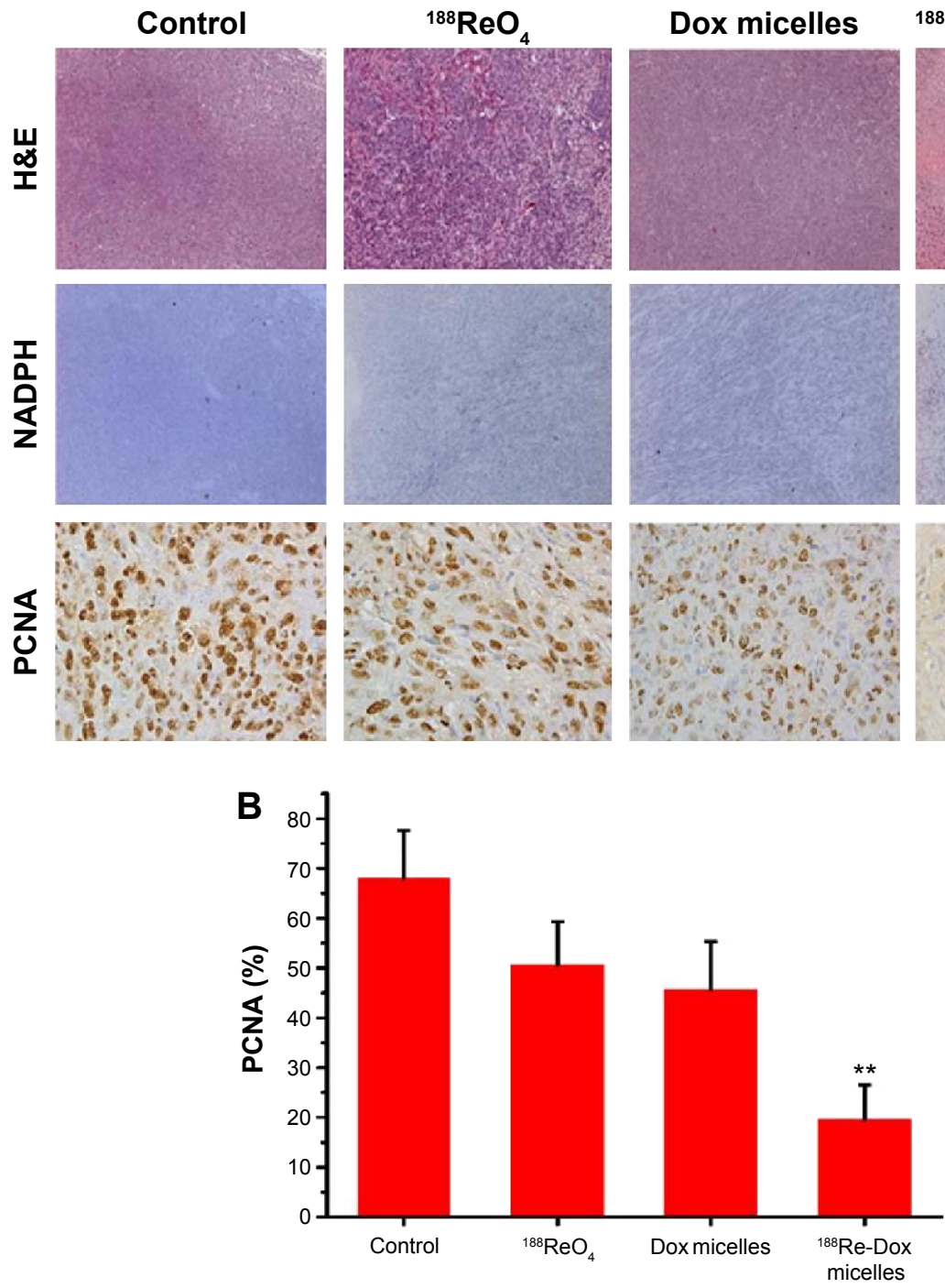

C
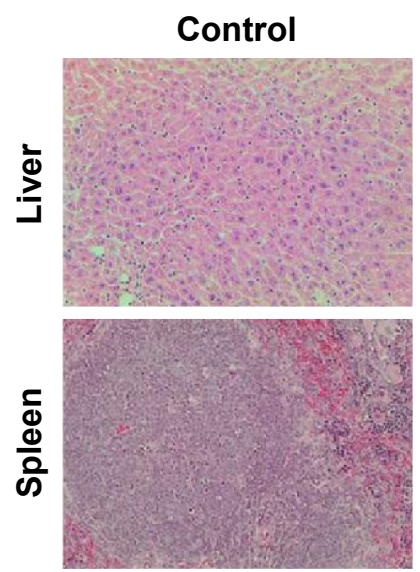
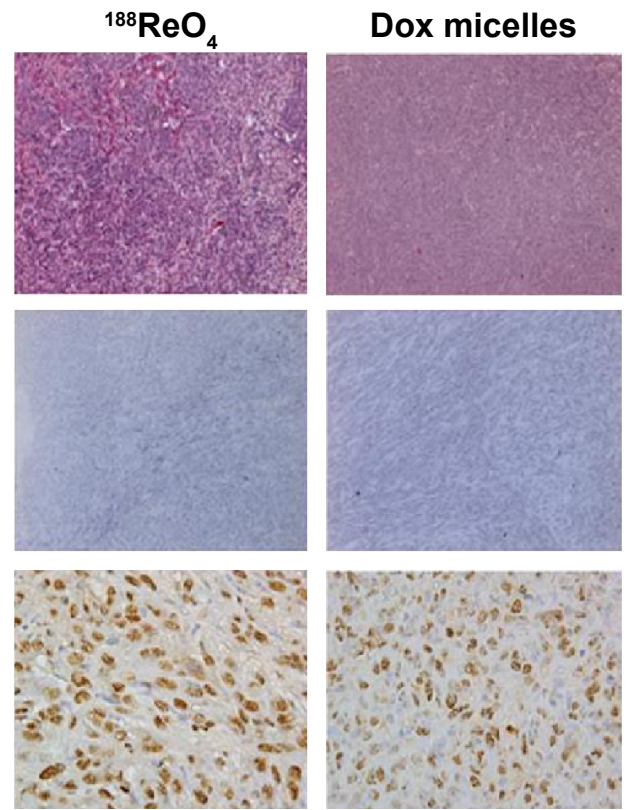

\section{Dox micelles}
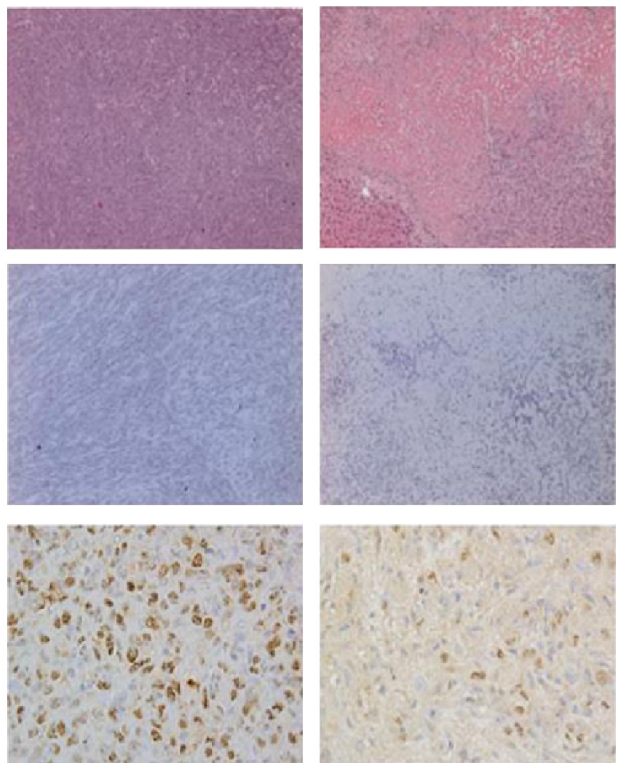

${ }^{188} \operatorname{Re}$-Dox micelles

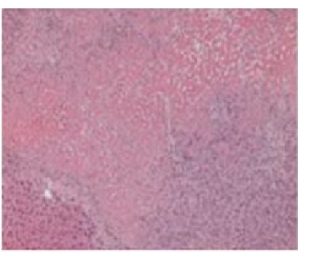

${ }^{188}$ Re-Dox micelles

$48 \mathrm{~h}$
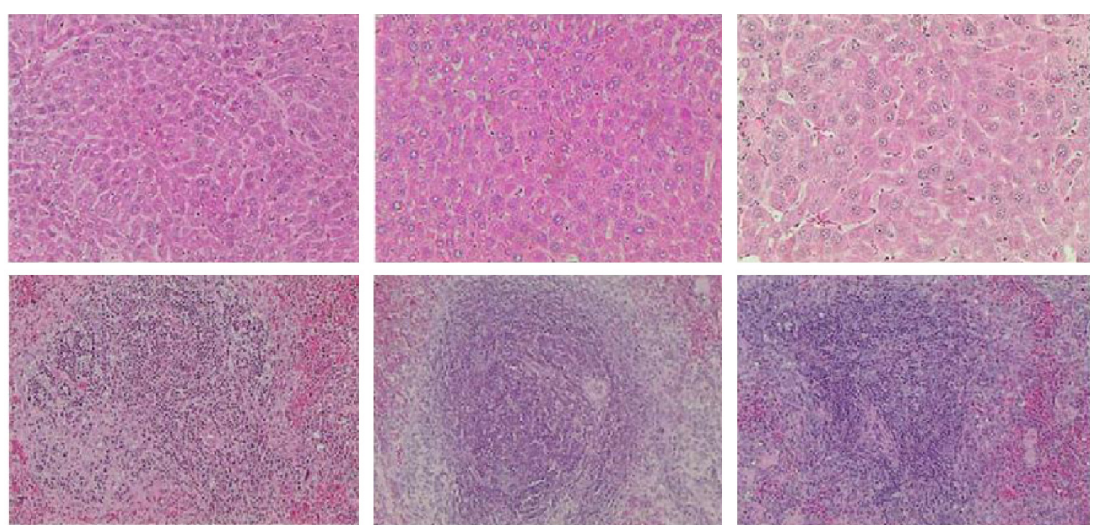

Figure 6 Immunohistochemical analysis of BNL/Luc hepatocellular carcinoma treated with ${ }^{188}$ Re-Dox micelles.

Notes: (A) H\&E staining and NADPH-diaphorase staining were imaged at $200 \times$ magnification. PCNA staining was imaged at $400 \times$ magnification. More necrotic tissue was found in the tumors of ${ }^{188} \mathrm{Re}$-Dox micelles (containing ${ }^{188} \mathrm{Re} 22.2 \mathrm{MBq}$ and Dox at $10 \mathrm{mg} / \mathrm{kg}$ ) group. (B) Cellular proliferation was quantified as the percentage of PCNApositive cells. All results are the mean \pm SD from ten distinct regions of each of the three tumors per experimental group. (C) Histological analysis of normal liver and spleen in mice treated with ${ }^{188}$ Re-Dox micelles. ${ }^{*} * P<0.01$ compared with other treatments.

Abbreviations: BNL/Luc, luciferase-transfected BNL tumor cells; d, days; Dox, doxorubicin; h, hours; H\&E, hematoxylin and eosin; NADPH, nicotinamide adenine dinucleotide phosphate; PCNA, proliferating cell nuclear antigen; ${ }^{188} \mathrm{Re}$, rhenium- I88; ${ }^{188} \mathrm{ReO}_{4},{ }^{188}$ Re-perrhenate; SD, standard deviation. 
doxorubicin found in the tumors. The result suggesting that after the uptake of the ${ }^{188} \mathrm{Re}$-Dox micelles by cancer cells, Dox was released as previously described. ${ }^{40}$

Comparatively, mice that received the ${ }^{188}$ Re-Dox micelles or Dox micelles alone shown significantly lower tumor burdens on day 6 and on day 13 than did those that received PBS or ${ }^{188} \mathrm{ReO}_{4}$ alone (Figure 5). Treatment with the ${ }^{188} \mathrm{Re}-\mathrm{Dox}$ micelles delayed the appearance and decreased the intensity of luminescence by up to days 26 ; however, the expression of luminescence did not decrease in the other groups. This suggests that the ${ }^{188} \mathrm{Re}$-Dox micelles were the inhibitoriest toward tumor growth compared with the other single treatments.

Although we observed body weight loss in mice receiving the ${ }^{188}$ Re-Dox micelles, all mice administered with triple doses of the ${ }^{188}$ Re-Dox micelles had survived on day 26 , indicating that the combination of radiotherapy and chemotherapy mediated by the ${ }^{188} \mathrm{Re}-\mathrm{Dox}$ micelles did not cause obvious toxicity (Figure 5).

In pathology studies (Figure 6), results of H\&E staining indicated that more necrosis was seen in tumors treated with the ${ }^{188}$ Re-Dox micelles, such as coagulation, vacuolation, and decreased nuclear staining in tumor tissues as described previously. ${ }^{18}$ This was in good agreement with the loss of NADPH-diaphorase activity. ${ }^{35}$ The tumor tissue sections of all experiment groups were stained with NADPH-diaphorase staining for the assessment of tissue viability. Necrotic tissue in tumor sections showed loss of NADPH-diaphorase activity. ${ }^{35}$ As shown in Figure 6A, the tumor treated with ${ }^{188} \mathrm{Re}$-Dox micelles had more necrotic features than that treated with ${ }^{188} \mathrm{ReO}_{4}$ alone or Dox micelles alone. PCNA staining shown high expression in tumors treated with ${ }^{188} \mathrm{ReO}_{4}$, Dox micelles, and PBS alone, but very low in tumors treated with the ${ }^{188}$ Re-Dox micelles (Figure 6B). According to the results of immunohistochemical staining, the ${ }^{188} \mathrm{Re}-$ Dox micelles cause cell death through necrosis. These imply that the treatment with the ${ }^{188} \mathrm{Re}-\mathrm{Dox}$ micelles could greatly increase tumor necrosis and reduce the tumor proliferation but not cause significant toxicity in normal liver and spleen (Figure 6C).

\section{Conclusion}

In summary, we had prepared and characterized multifunctional ${ }^{188}$ Re-Dox micelles simultaneously loaded with doxorubicin and labeled with ${ }^{188} \mathrm{Re}$ for cancer radiotherapy combined with chemotherapy. The components in the ${ }^{188}$ Re-Dox micelles acted synergistically against tumor growth, demonstrating better performance than either component $\left({ }^{188} \mathrm{ReO}_{4}\right.$ or Dox micelles) individually in mice bearing orthotopic liver tumors. Therefore, the ${ }^{188} \mathrm{Re}-\mathrm{Dox}$ micelles would be a synergistic combinatorial treatment modality with both radiotherapy and chemotherapy for orthotopic HCC in mice model.

\section{Author contributions}

Ying-Hsia Shih designed the experiments, wrote the manuscript, and performed the experiments. Cheng-Liang Peng contributed to experimental suggestions and performed the experiments. Ping-Fang Chiang performed the experiments. Wuu-Jyh Lin contributed to experimental suggestions. TsaiYueh Luo contributed to experimental design and suggestions, and manuscript revision. Ming-Jium Shieh contributed to experimental suggestions and manuscript revision. All authors contributed toward data analysis, drafting and critically revising the paper, gave final approval of the version to be published, and agree to be accountable for all aspects of the work.

\section{Acknowledgments}

This research was funded by the National Science Council of the Republic of China (Taiwan) (NSC 102-2320-B-002038-MY3) and the Ministry of Health and Welfare, Taiwan (MOHW103-TDU-N-211-133006).

\section{Disclosure}

The authors report no conflicts of interest in this work.

\section{References}

1. Parkin DM, Bray F, Ferlay J, Pisani P. Global cancer statistics, 2002. Ca-a Cancer J Clin. 2005;55(2):74-108.

2. Cha C, DeMatteo RP, Blumgart LH. Surgery and ablative therapy for hepatocellular carcinoma. J Clin Gastroenterol. 2002;35(5):S130-S137.

3. Park S, Yoon J, Bae S, et al. Therapeutic use of $\mathrm{H}_{2} \mathrm{O}_{2}$-responsive antioxidant polymer nanoparticles for doxorubicin-induced cardiomyopathy. Biomaterials. 2014;35(22):5944-5953.

4. Zheng L, Gou M, Zhou S, et al. Antitumor activity of monomethoxy poly(ethylene glycol)-poly (epsilon-caprolactone) micelle-encapsulated doxorubicin against mouse melanoma. Oncol Rep. 2011;25(6):1557-1564.

5. Lv S, Tang Z, Li M, et al. Co-delivery of doxorubicin and paclitaxel by PEG-polypeptide nanovehicle for the treatment of non-small cell lung cancer. Biomaterials. 2014;35(23):6118-6129.

6. Gray B, Van Hazel G, Hope M, et al. Randomised trial of SIR-spheres $((\mathrm{R}))$ plus chemotherapy vs chemotherapy alone for treating patients with liver metastases from primary large bowel cancer. Ann Oncol. 2001 12(12):1711-1720

7. Gulec SA, Mesoloras G, Dezarn WA, McNeillie P, Kennedy AS. Safety and efficacy of Y-90 microsphere treatment in patients with primary and metastatic liver cancer: the tumor selectivity of the treatment as a function of tumor to liver flow ratio. J Transl Med. 2007;5:15.

8. Wang S-J, Lin W-Y, Lui W-Y, Chen M-N, Tsai Z-T, Ting G. Hepatic artery injection of yttrium-90-lipiodol: biodistribution in rats with hepatoma. J Nucl Med. 1996;37(2):332-335.

9. Hamoudeh M, Kamleh MA, Diab R, Fessi H. Radionuclides delivery systems for nuclear imaging and radiotherapy of cancer. Adv Drug Deliv Rev. 2008;60(12):1329-1346. 
10. Luo T-Y, Tang IC, Wu Y-L, et al. Evaluating the potential of ${ }^{188} \mathrm{Re}-$ SOCTA-trastuzumab as a new radioimmunoagent for breast cancer treatment. Nucl Med Biol. 2009;36(1):81-88.

11. Gref R, Minamitake Y, Peracchia MT, Trubetskoy V, Torchilin V, Langer R. Biodegradable long-circulating polymeric nanospheres. Science. 1994;263(5153):1600-1603.

12. Kwon GS, Okano T. Polymeric micelles as new drug carriers. Adv Drug Deliv Rev. 1996;21(2):107-116.

13. Savic R, Luo LB, Eisenberg A, Maysinger D. Micellar nanocontainers distribute to defined cytoplasmic organelles. Science. 2003;300(5619): 615-618.

14. Shahin M, Ahmed S, Kaur K, Lavasanifar A. Decoration of polymeric micelles with cancer-specific peptide ligands for active targeting of paclitaxel. Biomaterials. 2011;32(22):5123-5133.

15. Peng CL, Lai PS, Lin FH, Wu SYH, Shieh MJ. Dual chemotherapy and photodynamic therapy in an HT-29 human colon cancer xenograft model using SN-38-loaded chlorin-core star block copolymer micelles. Biomaterials. 2009;30(21):3614-3625.

16. Matsumura Y. Preclinical and clinical studies of NK012, an SN-38incorporating polymeric micelles, which is designed based on EPR effect. Adv Drug Deliv Rev Deliv Rev. 2011;63(3):184-192.

17. Peng C-L, Shih Y-H, Lee P-C, Hsieh TM-H, Luo T-Y, Shieh M-J. Multimodal image-guided photothermal therapy mediated by Re-188labeled micelles containing a cyanine-type photosensitizer. ACS Nano. 2011;5(7):5594-5607.

18. Peng C-L, Shih Y-H, Liang K-S, et al. Development of in situ forming thermosensitive hydrogel for radiotherapy combined with chemotherapy in a mouse model of hepatocellular carcinoma. Mol Pharm. 2013;10(5):1854-1864.

19. Shieh MJ, Peng CL, Chiang WL, et al. Reduced skin photosensitivity with meta-tetra(hydroxyphenyl)chlorin-loaded micelles based on a poly(2-ethyl-2-oxazoline)-b-poly(d,1-lactide) diblock copolymer in vivo. Mol Pharm. 2010;7(4):1244-1253.

20. Tang IC, Luo T-Y, Liu S-W, et al. Synthesis and application of ${ }^{188} \mathrm{Re}-\mathrm{MN}-16 \mathrm{ET} / \mathrm{lipiodol}$ in a hepatocellular carcinoma animal model. Nucl Med Biol. 2011;38(7):1043-1052.

21. Lin W-Y, Luo T-Y, Tsai S-C, Kao C-H, Tang IC, Huang P-W. A comparison of Re-188-MN-16ET-lipiodol and transcatheter arterial chemoembolization in the treatment of hepatoma: an animal study. $\mathrm{Nucl}$ Med Biol. 2013;40(3):437-441.

22. Huang P-W, Tsai S-C, Luo T-Y, Kao C-H, Lin W-Y. Therapeutic efficacy of ${ }^{188}$ Re-MN-16ET lipiodol in an animal model of hepatocellular carcinoma. Ann Nucl Med. 2013;27(6):532-537.

23. Bertrand N, Wu J, Xu X, Kamaly N, Farokhzad OC. Cancer nanotechnology: the impact of passive and active targeting in the era of modern cancer biology. Adv Drug Deliv Rev. 2014;66:2-25.

24. Wu J, Akaike T, Maeda H. Modulation of enhanced vascular permeability in tumors by a bradykinin antagonist, a cyclooxygenase inhibitor, and a nitric oxide scavenger. Cancer Res. 1998;58(1):159-165.

25. Ferrari M. Nanogeometry: beyond drug delivery. Nat Nano. 2008;3(3): $131-132$.
26. Popović Z, Liu W, Chauhan VP, et al. A nanoparticle size series for in vivo fluorescence imaging. Angew Chem Int Ed. 2010;49(46): 8649-8652.

27. Cabral H, Matsumoto Y, Mizuno K, et al. Accumulation of sub- $100 \mathrm{~nm}$ polymeric micelles in poorly permeable tumours depends on size. Nat Nano. 2011;6(12):815-823.

28. Wu J, Chu C-C. Block copolymer of poly(ester amide) and polyesters: synthesis, characterization, and in vitro cellular response. Acta Biomater. 2012;8(12):4314-4323.

29. Peng CL, Shieh MJ, Tsai MH, Chang CC, Lai PS. Self-assembled star-shaped chlorin-core poly(c-caprolactone)-poly(ethylene glycol) diblock copolymer micelles for dual chemo-photodynamic therapies. Biomaterials. 2008;29(26):3599-3608.

30. Fonge H, Lee H, Reilly RM, Allen C. Multifunctional block copolymer micelles for the delivery of 111 In to EGFR-positive breast cancer cells for targeted auger electron radiotherapy. Mol Pharm. 2009;7(1): 177-186.

31. Cheng CC, Huang CF, Ho AS, et al. Novel targeted nuclear imaging agent for gastric cancer diagnosis: glucose-regulated protein 78 binding peptide-guided In-111-labeled polymeric micelles. Int J Nanomed. 2013;8:1385-1391.

32. Cheng CC, Lu N, Peng CL, et al. Targeting to overexpressed glucoseregulated protein 78 in gastric cancer discovered by 2D DIGE improves the diagnostic and therapeutic efficacy of micelles-mediated system. Proteomics. 2012;12(15-16):2584-2597.

33. Chen Y, Xiong Q-F, Yang X-Q, He L, Huang Z-W. Evaluation of ${ }^{188}$ ReDTPA-deoxyglucose as a potential cancer radiopharmaceutical. Am J Roentgenol. 2010;194(3):761-765.

34. Hsieh B-T, Hsieh J-F, Tsai S-C, et al. Rhenium-188-labeled DTPA: a new radiopharmaceutical for intravascular radiation therapy. $\mathrm{Nucl} \mathrm{Med}$ Biol. 1999;26(8):967-972.

35. Zuchini R, Huang CH, Tsai HW, et al. Electromagnetic thermoablation to treat thrombocytopenia in cirrhotic and hypersplenic rats. J Gastroenterol Hepatol. 2010;25(9):1578-1586.

36. Litzinger DC, Buiting AMJ, Vanrooijen N, Huang L. Effect of liposome size on the circulation time and intraorgan distribution of amphipathic poly(ethylene glycol)-containing liposomes. Biochim Biophys Acta Biomembr. 1994;1190(1):99-107.

37. Moghimi SM, Hunter AC, Murray JC. Long-circulating and targetspecific nanoparticles: theory to practice. Pharmacol Rev. 2001;53(2): 283-318.

38. Poste G, Kirsh R. Site-specific (targeted) drug delivery in cancer therapy. Nat Biotechnol. 1983;1(10):869-878.

39. Fisher JW, Sarkar S, Buchanan CF, et al. Photothermal response of human and murine cancer cells to multiwalled carbon nanotubes after laser irradiation. Cancer Res. 2010;70(23):9855-9864.

40. Lu P-L, Chen Y-C, Ou T-W, et al. Multifunctional hollow nanoparticles based on graft-diblock copolymers for doxorubicin delivery. Biomaterials. 2011;32(8):2213-2221.
International Journal of Nanomedicine

\section{Publish your work in this journal}

The International Journal of Nanomedicine is an international, peerreviewed journal focusing on the application of nanotechnology in diagnostics, therapeutics, and drug delivery systems throughout the biomedical field. This journal is indexed on PubMed Central, MedLine, CAS, SciSearch $®$, Current Contents ${ }^{\circledR} /$ Clinical Medicine,
Dovepress

Journal Citation Reports/Science Edition, EMBase, Scopus and the Elsevier Bibliographic databases. The manuscript management system is completely online and includes a very quick and fair peer-review system, which is all easy to use. Visit http://www.dovepress.com/ testimonials.php to read real quotes from published authors. 